\title{
USE OF CELLULOSE FIBERS FROM HEMP CORE IN FIBER-CEMENT PRODUCTION. EFFECT ON FLOCCULATION, RETENTION, DRAINAGE AND PRODUCT PROPERTIES
}

\section{R. Jarabo ${ }^{a}$, E. Fuente ${ }^{a}$, M.C. Monte ${ }^{a^{*}}$, H. Savastano Jr. ${ }^{\text {b }}$ P. Mutjé ${ }^{c}$ and C. Negro ${ }^{a}$.}

a. Chemical Engineering Department, Complutense University of Madrid. Avda. Complutense s/n, Madrid 28040. Spain

b.Faculdade de Zootecnia e Engenharia de Alimentos, Universidade de São Paulo, Avenida Duque de Caxias Norte, 225, 13635-900. Pirassununga, SP, Brazil

c. Grup LEPAMAP. Universitat de Girona. Avd. Lluís Santaló, S/N. 17071- Girona, Spain

\section{ABSTRACT}

The aim of this paper is to study the feasibility of using cellulose fibers obtained from an agricultural waste, hemp core (Cannabis Sativa L.), through different new environmental friendly cooking processes for fiber-cement production. The physical and mechanical properties of the fiber reinforced concrete, which depend on the nature and morphology of the fibers, matrix properties and the interactions between them, must be kept between the limits required for its application. Therefore, the morphology of the fibers and how its use affects the flocculation, retention and drainage processes in the fiber-cement manufacture, and the mechanical and physical properties of the fiber-cement product have been studied.

The use of pulp obtained by means of the hemp core cooking in ethanolamine at $60 \%$ concentration at $180{ }^{\circ} \mathrm{C}$ during 90 minutes resulted in the highest solids retention and the best mechanical properties among the studied hemp core pulps.

\section{Keywords:}

Fiber-cement; Pulping conditions; Hemp core; Agricultural wastes; Flocculation. 26

* Corresponding author: Ma Concepción Monte. Chemical Engineering Department, Chemistry Faculty. Complutense University of Madrid. Avda. Complutense s/n, Madrid 28040. Spain. Phone:+34 9139442 45. e-mail: cmonte@quim.ucm.es 


\section{INTRODUCTION}

The use of agricultural wastes as reinforcement of composite materials is one of the most important targets in today's materials research (Ahankari et al., 2011; Ashori and Nourbakhsh, 2010; Rabi et al., 2009). The present research is concerned with the use of the wastes from the industrial hemp, Cannabis Sativa L., to obtain useful cellulose fibers to manufacture fiber-cement products for roofing. Industrial hemp is one of the crops having a highest yield among those of temperate zones, being at the same time one of and less intensive ones. It is highly self-compatible what means that it requires crop rotation. Similar to other lignocellulosic fibers, hemp is biodegradable and environmentally friendly (Mutjé et al., 2007). This, together with its high strength and durability and low density, explains the increase in the use of hemp fibers in the manufacture of composite materials (Carver, 1941; Hayo, 2004). The most common material obtained from hemp is its fibers, especially the coarse ones which are extremely strong and durable. As the most valuable fibers are located in the phloem, they must often be separated from the xylem material ("hemp core"), which is considered a waste in the hemp industry (Sedan et al., 2008; Troëdec et al., 2011).

The use of cellulose fibers as reinforcing agents in composite building materials offers many advantages over glass fibers, such as the possibility to manufacture products with low density and good biodegradability (Joshi et al., 2004; Li et al., 2006; Mwaikambo and Ansell, 2003). However, cellulose fibers also have some disadvantages, for instance, they present low modulus of elasticity, high moisture absorption, they decompose in alkaline environments and are susceptible to biological attack, and they have variable mechanical and physical properties (Swamy, 1990). Some of these disadvantages could be overcome by using fibers 
56 from hemp core with a higher durability than the traditional cellulose fibers from

57 pine and with a specific tensile strength of $0.750 \mathrm{GPa}$, and specific modulus of

58 elasticity of $60 \mathrm{GPa}$. These properties make hemp fibers a candidate material with

59 potential as reinforcement fiber (Li et al., 2004).

60 Many authors have studied the use of hemp fibers as reinforcement for building

61 materials based on cement (Dalmay et al., 2010; Placet, 2009; Sedan et al., 2008;

62 Troëdec et al., 2011). However, the use of hemp core fibers for this purpose has

63 not been yet reported. This research aims to contribute to fill this lack of

64 knowledge.

65 In general, cell wall polymers and their matrices determine the mechanical and 66 physical properties of natural fibers. In view of this, a number of researchers have 67 reported the chemical composition of natural cellulose fibers and some of them 68 have recommended improving the natural cellulose fiber properties by modifying 69 the cell wall polymers (Golbabaie, 2006; Wielage et al., 2003; Young, 1997). 70 Furthermore, the incorporation of cellulose fibers in a polymer or mineral matrix 71 can involve an interface incompatibility between fibers and matrix, which may be 72 overcome through the chemical pretreatment of fibers, with the aim of modifying 73 either the chemical nature of the fiber surface or the surface properties (e.g., 74 electrostatic charge, conformation of adsorbed polymers). The effect of this 75 treatment is probably a modification of the interactions between the mineral matrix 76 and fibers, which increases the efficiency with which stress is transferred from the 77 matrix to the fiber (Negro et al., 2005; Ouajai and Shanks, 2005).

78 The process through which fibers are obtained from natural sources determines the 79 properties of the fibers surface and, therefore, it affects the interface matrix-fiber 80 surface. To study the effect of this stage on the final product two different 
81 treatments, namely a semi-chemical pulping process and a chemical pulping

82 process, both at different cooking conditions have been applied to obtain the

83 cellulose fibers from the hemp core.

84 First, a comprehensive study of the morphology of the fibers was carried out

85 (Jarabo et al., 2012); then, the effect of using these fibers on the fiber-cement

86 manufacture process was determined through the study of the flocculation,

87 retention and drainage of the fiber-cement suspensions prepared with the different

88 fibers. Finally, the effect of using the obtained fibers on the physical and

89 mechanical properties of fiber-cement probes was determined.

\section{2. MATERIALS AND METHODS}

\section{$91 \quad$ 2.1. Materials}

92 The raw material used for this study was the hemp core, waste from the culture of

93 Cannabis Sativa L. grown in Spain and supply by the LEPAMAP Group.

94 The hemp fiber is constituted by $43 \%$ cellulose, $16 \%$ hemicellulose and $8 \%$ lignin.

95 Hemp straw is a sub-product in the process to obtain hemp strands from stalk of

96 the plant. This stalk can be separated, or decorticated, into two main components:

97 fibers and core fibers. The initial length of these core fibers lies between 5 and 10

98 mm (Mutjé et al., 2007; Barberà et al., 2011).

99 Tables 1 and 2 show the cooking conditions used to obtain hemp pulp by a semi-

100 chemical process and a chemical (organosolv) process employing $\mathrm{NaOH}$ and

101 ethanolamine as solvents, respectively and the yield obtained in each case.

102 The ethanolamine PA-ACS solution was supplied as a commercial product by

103 Panreac.

104 Organosolv pulping were performed in a 25-L stainless steel rotator digester with a 105 heat exchanger system and pressure control. The pulping conditions were 
maintained constant as follows: liquor to solid ratio: 6:1 and digester pressure 5-7 bars. Selected experimental conditions were: solvent concentration, temperature and pulping time.

The pulping with $\mathrm{NaOH}$ was carried out in the same digester but with a solution of $\mathrm{NaOH}$ having $1.4 \mathrm{~g} / \mathrm{L}$ of anthraquinone as a catalyzer of the chemical reaction. The cooked pulps were defibred in a hydrapulper and screened through a Somerville vibratory flat screen with $0.15 \mathrm{~mm}$ slot size; the screened pulp was washed, pressed, crumbled and stored at $4{ }^{\circ} \mathrm{C}$.

The conditions chosen in these tables are the result best from a previous study carried out to optimize these cooking processes for hemp core fibers (Barberà et al., 2011).

Refined unbleached pine Kraft pulps ( $\left.35^{\circ} \mathrm{SR}\right)$ were used as reference since this pulp is commonly used to provide cellulose fibers in the manufacture of fibercement through the Hatschek process.

A Portland cement (type II / AV 42.5) containing 12\% fly ash was used for the probes. It is a fine powder with a wide distribution of particle sizes, being the $80 \%$ of the particles in the interval from $2 \mu \mathrm{m}$ to $50 \mu \mathrm{m}$.

Microsilica was also used to manufacture of the test probes. The type of microsilica employed was composed of ultra-thin amorphous spheres of $\mathrm{SiO}_{2}$ with a particle size around $0.5 \mu \mathrm{m}$ containing small amounts of crystalline quartz (less than $0.5 \%$ ) as impurities.

The flocculant employed to study the behavior of fiber-cement suspensions and to prepare the fiber-cement probes was an anionic polyacrylamide (APAM) commonly used in the industrial Hatschek process (Negro et al., 2006) with a molecular weight of $7.4 \cdot 10^{6} \mathrm{~g} / \mathrm{mol}$ and a charge density of $13.4 \%$. The flocculant 
131 was dissolved in distilled water to prepare solutions of APAM with a 132 concentration of $1.5 \mathrm{~g} / \mathrm{L}$.

133 The composition of the prepared fiber-reinforced cement slurries is summarized in

134 Table 3. Five fiber-cement slurries were prepared, being the source of cellulose the 135 only difference between them: M1 was prepared using pulp P1 as a source of 136 cellulose fibers, M2 was prepared with P2, M3 with P3, M4 with P4 and the pine 137 Kraft pulp was used to prepare the fiber-cement slurry MR, which was used as a 138 reference.

139 Although in air curing fiber-cements synthetic fibers (PVA) are normally used due 140 to their capacity to withstand degradation due to environmental conditions, in the 141 present research, no synthetic fibers were used to prepare the probes so as to avoid 142 interferences in the determination of the fiber-cement properties that can be 143 ascribed to the use of cellulose fibers.

\section{$144 \quad$ 2.2. Methods}

\section{$145 \quad$ 2.2.1. Density of the fibers}

146 The fiber density was measured by using a gas pycnometer (Multipycnometer).

147 Helium was the gas employed because its small atomic radius enables it to enter

148 into crevices and pores approaching one Angstrom $\left(10^{-10} \mathrm{~m}\right)$.

149 Before the measurement, the samples were dried in an oven at $60{ }^{\circ} \mathrm{C}$ for $24 \mathrm{~h}$. The 150 volume of each sample was determined five times applying Equations 1-2 to the 151 pressure and volume values measured:

152

153

$$
\mathrm{Vp}\left(\mathrm{cm}^{3}\right)=\mathrm{V}_{\mathrm{c}}-\mathrm{V}_{\mathrm{r}}\left(\left(\mathrm{P}_{1} / \mathrm{P}_{2}\right)-1\right)
$$

154

Density $\left(\mathrm{g} / \mathrm{cm}^{3}\right)=\mathrm{W} / \mathrm{V}_{\mathrm{p}}$ 
Where: $\mathrm{V}_{\mathrm{p}}$ is the sample volume, $\mathrm{V}_{\mathrm{c}}$ is the volume of the sample holder (16.163

$\left.\mathrm{cm}^{3}\right), \mathrm{V}_{\mathrm{r}}$ is the reference volume $\left(8.068 \mathrm{~cm}^{3}\right), \mathrm{P}_{1}$ is the pressure measurement after pressurizing the reference volume (PSI), $\mathrm{P}_{2}$ is the pressure measurement after including $\mathrm{V}_{\mathrm{c}}(\mathrm{PSI})$ and the $\mathrm{W}$ is the dry weight of sample.

\subsubsection{Morphological characterization of fibers}

161 The morphological characterization of the fibers was carried out by using a fiber 162 and pulp morphological analyzer, Morfi, V7.9.13.E (Techpap, France).

163 This characterization is based on an image analysis system, consisting of a diode

164 that emits unpolarized light and a microcamera. Imaging is performed until the

165 equipment counts 5000 fibers, which is the optimum value for subsequent

166 statistical analysis, which is performed using a computer software. The images

167 were analyzed using a specific program to determine different parameters of the

168 fibers and pulps: fibers, arithmetic length, length weighted in length, average

169 length weighted in area, average width, coarseness, number of microfibrills and 170 fines length.

171 Fines are generated mainly during the beating stage when the pulps were defibred.

172 There are differentiated from the fibers by their dimensions. The equipment was

173 programmed to consider fiber length values between 100 and $10000 \mu \mathrm{m}$, width

174 between 5 and $75 \mu \mathrm{m}$, fines length below $100 \mu \mathrm{m}$ and width below $5 \mu \mathrm{m}$ (Jarabo,

175 et al., 2012; Moral et al., 2010).

176 The samples for morphological characterization were prepared by adding $1 \mathrm{~g}$ of 177 dry fibers to $600 \mathrm{~mL}$ of water and homogenizing the suspension in a laboratory 178 disintegrator ENJO- 692. The characterization was done in duplicates.

$179 \quad$ 2.2.3. Flocculation of fiber-cement suspension 
180 A commercial focused beam reflectance measurement probe (FBRM) M500L,

181 manufactured by Mettler Toledo, USA, was employed to monitor the flocculation

182 process and to determine the properties of the flocs. The FBRM device measures

183 the chord length distribution on real time over a wide interval of solid

184 concentrations. A laser beam is generated by a diode and focused on a focal point

185 in the plane next to the external surface of the probe window, which is inside the

186 suspension. The focal point describes a circular path at a constant speed of 2000

$187 \mathrm{~m} / \mathrm{s}$ due to the rotation of the focusing lens. When a particle intercepts the focal

188 point path, the reflected light reaches the detector through the probe and the optical

189 fiber. The detector receives light pulses. A chord length of the intercepting particle

190 is determined as the product of the time duration of the light pulse by the linear

191 speed of the focal point movement. Thousands of particles can be measured each

192 second. In this way, a chord length distribution is obtained from the light pulses

193 received during the measurement time (set in $5 \mathrm{~s}$ in this case). Each distribution is

194 a function of the size and shape of particles in suspension. The evolution of the

195 chord size distribution reflects the aggregation or dispersion of particles. Many

196 statistical parameters can be calculated from the distribution to follow its

197 evolution, e.g., the mean chord size and the total number of counts measured per

198 second (Blanco et al., 2002; Hubbe, 2007; Kerekes and Schell, 1992; Negro et al., 199 2007).

200 In the present study, the flocculation trials were carried out immersing the probe in 201 a $400 \mathrm{~mL}$ fiber-cement suspension, prepared with water saturated in $\mathrm{Ca}(\mathrm{OH})_{2}$, and 202 stirred at $800 \mathrm{rpm}$. After $10 \mathrm{~min}$, stirring intensity was reduced to $400 \mathrm{rpm} .100$ 203 ppm of APAM was added 5 min later, to induce flocculation, and the evolution of 204 the flocs was studied at $400 \mathrm{rpm}$ for $4 \mathrm{~min}$. After that, the stirring intensity was 
205 increased to $800 \mathrm{rpm}$ to break down the flocs formed (deflocculation) for $2 \mathrm{~min}$

206 and, finally, stirring intensity was reduced again to $400 \mathrm{rpm}$ to induce the

207 reflocculation of the system (Jarabo et al., 2010).

$208 \quad$ 2.2.4. Retention and drainage of fiber-cement suspension

209 The equipment used for measuring the retention and drainage was a vacuum

210 drainage tester (VDT). It has two jars separated by a barrier: the upper jar keeps

211 the fiber-cement suspensions stirred up to the addition of the flocculant dosage.

212 The second jar contains a mesh in the bottom to carry out the dewatering of the

213 suspension and it is connected to a vacuum pump and to a probe in which the

214 filtrate is stored and weighted in real time. The final volume of filtrate is

215 measured. In a typical trial, $400 \mathrm{~mL}$ of fiber-cement suspension, prepared with

216 water saturated in $\mathrm{Ca}(\mathrm{OH})_{2}$, were stirred at $600 \mathrm{rpm}$ during $6 \mathrm{~min}$ in the upper jar.

217 Then, stirring intensity was decreased to $300 \mathrm{rpm}$ and, 5 min later $100 \mathrm{ppm}$ of

218 APAM were added. After $15 \mathrm{~s}$ of contact time between flocculant and mixture, the

219 stirring was stopped, the barrier was removed and the suspension was drained to

220 the second jar in which an 18 mesh wire was placed. The suspension was drained

221 under vacuum (0.2 atm) through the filter and a computerized balance recorded the

222 mass of drained water over time. The drainage curve was analyzed in order to

223 obtain the drainage rate for the different flocculants. Retention and cake humidity

224 were determined gravimetrically after the analysis of the formed cake (Fuente et

225 al., 2010).

226 2.2.5. Preparation of fiber-cement probes

227 Fiber reinforced cement probes were prepared in the laboratory through a slurry

228 vacuum de-watering technique. The matrix materials were added and dispersed in

$229 \mathrm{Ca}(\mathrm{OH})_{2}$ saturated water with a solids concentration of $20 \%$. The slurry was 
230 transferred to an evacuable $200 \times 200 \mathrm{~mm}^{2}$ casting box and a vacuum $(\sim 60 \mathrm{KPa}$ 231 gauge) was exerted until excess water was removed and a solid cake was formed. 232 The pad was pressed at 3.2 MPa, so that the rest of the water was removed. After 233 pressing, the plates were sealed in a plastic bag at room temperature. Three pads 234 were prepared in this way for each formulation. After two days; the pads were 235 removed from the bags and placed in water. Twenty-six days later, the pads were 236 removed from the water and four $200 \times 50 \mathrm{~mm}^{2}$ flexural test specimens were 237 diamond wet-sawn from each pad. Eight pads were prepared to provide sufficient 238 specimens for the determination of mechanical properties and four pads were 239 prepared for the determination of physicals properties.

$240 \quad$ 2.2.6. Mechanical properties of fiber-cement probes

241 Mechanical tests were performed in the universal testing machine Emic DL-30,000 242 equipped with $1 \mathrm{KN}$ load cell. A four point bending configuration was employed 243 in the determination of modulus of rupture $(M O R)$, limit of proportionality $(L O P)$, 244 modulus of elasticity $(M O E)$ and specific energy $(S E)$ of the specimens following 245 calculations specified in Equations 3-6.

246 A span of $100 \mathrm{~mm}$ and a deflection rate of $0.5 \mathrm{~mm} / \mathrm{min}$ were used in the bending 247 test (Savastano et al., 2000). Test data were digitally recorded and reduced using 248 automatic data collection and processing facilities. Eight flexural specimens were 249 tested for each composite formulation.

250

$251 \quad \operatorname{MOR}(M P a)=\left(L_{M A X} /\left(b \cdot h^{2}\right)\right) \cdot\left(S_{\text {down }}-S_{\text {up }}\right)$

$252 L \mathrm{LOP}(\mathrm{MPa} a)=\left(L_{L O P} /\left(b \cdot h^{2}\right)\right) \cdot\left(S d_{o w n}-S_{\text {up }}\right)$

$253 \operatorname{MOE}(k P a)=\operatorname{tg} \alpha\left(L_{M A X} / \delta\right) \cdot\left(S_{\text {down }}-S_{\text {up }}\right)^{3} /\left(b \cdot h^{3}\right)$

$254 S E\left(k J / m^{2}\right)=$ Absorbed energy $/(b \cdot h)$ 
256 Where $\mathrm{L}_{\text {MAX }}$ is the maximum stress, $\mathrm{L}_{\mathrm{LOP}}$ is the stress at the upper point of the 257 linear portion of the stress-strain curve, $\left(S_{\text {down }}-S_{\text {up }}\right)$ is the major span, $\mathrm{b}$ and $\mathrm{h}$ are 258 the specimen width and thickness respectively, $\operatorname{tg} \alpha$ is the initial slope of the stress259 strain curve and $\delta$ is the deflection of the composite.

260 The absorbed energy is the area under the stress-strain curve to the point 261 corresponding to a reduction in carrying capacity to the maximum stress (Tonoli et 262 al., 2010).

263 The mechanical properties of the probes were measured 28 days after the 264 construction of the sheet.

$265 \quad$ 2.2.7. Physical properties of fiber-cement suspension

266 Water absorption, bulk density and porosity values at 28 days were obtained from

267 the tested flexural specimens following the procedures specified in ASTM C 948-

$268 \quad 81$ (ASTM C 948-81).

269 Four specimens were used to determine these properties.

270 3. RESULTS

$271 \quad 3.1$ Morphological characterization of pulps

272 The results of the morphological characterization of hemp core fibers and pulps

273 obtained by both semi-chemical and organosolv process are shown in Table 4.

$274 \quad$ Kraft pine pulp was also characterized for comparison.

275 It is noticeable that the length of the fibers and fines obtained from the hemp core

276 is much shorter than that of the pine fibers. Therefore, the number the fibers per

277 gram on hemp pulps are higher than that on pine pulp. This could improve their 278 dispersion in the matrix. 
279 P1 and P3, presented lower values of fibers arithmetic length, length weighted in 280 length, average width and coarseness along which lower fines length than those for 281 the pulps P2 and P4. This can be due to the more aggressive cooking conditions 282 used to obtain pulps P1 and P3, which increase the probability of fibers 283 degradation during the process.

284 Regarding the effect of the process (semi-chemical or organosolv), the organosolv 285 pulps (P3 and P4) had slightly shorter fibers and with lower coarseness than the 286 semi-chemical pulps.

$287 \mathrm{NaOH}$ used in semi-chemical process is well-known to remove amorphous 288 materials, such as hemicelluloses and pectins, from the surface of hemp fibers 289 (Troëdec et al., 2009); this reduces the coarseness of the fibers, which is lower for 290 P1. However, the coarseness of the organosolv fibers is even lower than that of P1. 291 Organosolv process consists of dissolving lignin, extractives, hemicelluloses and 292 pectin in ethanolamine but in such way that they can be used to obtain valuable 293 chemical products. The efficiency of the organosolv process in removing these 294 compounds from the fiber surface is high even when soft cooking conditions is 295 applied.

296 The percentage of microfibrills is similar in pulps P2, P3 and PR and higher than 297 in the two other pulps. This could increase the interaction among the fibers and the 298 matrix and, consequently, improve the properties of the fiber-cement.

299 It has been demonstrated that a fiber analyzer (MorFi) can gain quick and reliable 300 results (Bartl and Pico, 2009; Pico and Bartl, 2011).

\section{$301 \quad 3.2$. Flocculation of fiber-cement mixtures}

302 Fig. 1 shows the evolution of the mean chord size of particles and flocs in cement $303 \quad$ suspensions. 
304 After $600 \mathrm{~s}$ of stirring at $400 \mathrm{rpm}$, the value of the mean chord size was constant.

$305900 \mathrm{~s}$ after starting the trial, the addition of flocculant to the suspension caused a

306 fast increase in the mean chord size due to the aggregation of particles to form

307 larger flocs. A maximum value of this parameter was reached at ten or fifteen

308 seconds and then it started decreasing with different rate depending on the stability

309 and strength of the flocs in such hydrodynamic conditions (evolution of flocs).

310 When the stirring was increased to $800 \mathrm{rpm}$, part of the remaining flocs was

311 broken, thus decreasing the mean chord size (deflocculation). The reflocculation

312 ability of the system is shown by the increase in the mean chord size when the

313 stirring was decreased to $400 \mathrm{rpm}$ again.

314 It can be observed that the largest maximum mean chord size was reached in the

315 MR suspension. This value, however, is not to different from those reached in

316 suspensions M2 and M4 and the evolution of the mean chord size in these two

317 cases indicates that the flocs formed were more stable than those formed from MR.

318 Moreover, after the deflocculation and reflocculation stages, the mean chord size

319 in M2 and M4 remained larger than in the case of the MR suspension. The

320 maximum mean chord size values reached in M1 and M3 were lower than those

321 reached in the other cases, but after the evolution stage the values obtained were

322 slightly lower than those in MR.

323 The results indicate that the flocculation process and floc properties are more

324 affected by the cooking conditions than by the cooking reagent used, and that the

325 use of soft cooking conditions favored the formation of larger and more stable

326 flocs when APAM was added to the fiber-cement pulp.

$327 \quad 3.3$. Retention and drainage of fiber-cement suspensions 
328 Fig. 2 shows the drainage curves of the fiber-cement suspensions considered in 329 this research.

330 Drainage took place in two steps: first, the suspension was filtrated and a cake was 331 formed with a fast water removal, which corresponds to the first part of the 332 drainage curves (linear part with a high slope); secondly, the cake was compressed 333 and thickened and water removal rate decreases towards zero. During the first 334 stage, only the water between flocs was removed, while part of the water inside the 335 flocs was removed during the compression stage. Most of the solids loss with the 336 filtrate takes place during the first stage while the second stage determines the final 337 humidity and the formation properties of the cake. Drainage time can be obtained 338 as the time required to reduce the drainage curve slope to zero.

339 There are notable differences between the drainage curves of the fiber-cement 340 suspensions containing hemp core fibers and the one for MR. The initial drainage 341 rate was notably affected by the intensity of cooking conditions of the pulp and it 342 took the lowest values for M1 and M3 suspensions. There was no appreciable 343 compression stage in the drainage curves of M2 and M4. The final weight of 344 recovered filtrate was also higher in these cases and in the case of M1.

345 Table 5 shows that the solids retention was very low when the cake was formed 346 from suspensions M2 and M4, taking its maximum value in the case of 347 suspensions M1 and M3. These values, together with the drainage curves, indicate 348 that most of the mineral solids, were lost with the water drained during the first 349 drainage stage in the case of M2 and M4 with only some of the mineral solids 350 remaining in the cake and the majority of fibers, whose high hygroscopicity 351 explains the high humidity of the cakes formed in these two cases. 
352 These differences can be explained from the chord size distribution of particles in 353 suspension after the flocculation process (Fig. 3) and from the floc properties.

354 Fig. 3 shows that the chord size distributions of flocculated suspensions M2, M4 355 and MR were similar, and that the flocs formed were much larger than in the case 356 of M1 and M3. Therefore, the spaces among the flocs are also larger and water can 357 drain very fast. This explains the high initial drainage rate observed by M2, M4 358 and MR. However, the flocs formed from MR are much weaker than those formed 359 from M2 and M4 and, therefore, they were broken, deformed and compressed by 360 the vacuum forces causing the spaces among the flocs to diminish, which implies a 361 decrease in the drainage rate (compression stage) and a higher retention of mineral $362 \quad$ solids.

363 The chord size distributions of M1 and M3 show that there were numerous small 364 flocs and particles present in these suspensions. The spaces among the flocs were, 365 therefore, smaller, what contributes to an increase in the retention of solids, but 366 causes a decrease in the drainage rate. The humidity of the cake decreases when 367 retention increases, and this is due to the higher mineral content of the cake (water 368 absorbed by the mineral particles is much less than water absorbed by the fibers).

\section{3.4. Mechanical and physical properties of the probes}

370 Fig. 4 shows the stress-strain curves of the specimens at 28 days. The curve 371 obtained with M3 resulted to be the most similar one to that obtained with MR is, 372 although it is worth noticing that the maximum elongation before the failure of the 373 probe was higher in the case of M3, while the maximum stress was lower. This 374 mechanical behavior, high elongation and stress reached, and the large area under 375 the curves can be associated with a good array of the fibers and solid particles into 
376 the composite. The other probes were more rigid than M3 and MR, as shown by

$377 \quad$ their low strain values.

378 Therefore, the probes prepared from M3 may be the ones with the best mechanical 379 properties among the fiber-cement probes prepared with hemp core fibers.

380 Fig. 5 shows the results of the mechanical properties: modulus of rupture, limit of 381 proportionality, elastic modulus and specific energy of the probes of fiber-cement 382 made of hemp pulps with the two applied processes.

383 These figures show that, among the mixtures with hemp core fibers, M3 yielded 384 the probes with the highest modulus of rupture, limit of proportionality and 385 specific energy, although these values were lower than the values obtained with 386 the reference MR. It is worth pointing out that the fibers used in the preparation of $387 \quad$ MR were refined fibers. Refining increases the presence of microfibrills and 388 degrade fiber surface, which enhances the interaction among fibers and matrix. 389 Pine fibers and fines lengths are notably greater than those of hemp core fibers and 390 these parameters also have a significant effect on the mechanical properties of the 391 probes. Fines do not contribute significantly to fiber-cement strength but act more 392 as filler and, in most cases, influence negatively the drainage of the suspension 393 (Tonoli et al., 2009).

394 Furthermore, Fig. 5 shows that the elastic modulus of the probes prepared from $395 \quad$ M4 were the highest, even higher than the values obtained for the reference 396 probes. This is due to the high value of $\operatorname{tg} \alpha$.

397 A larger number of fibers per gram could be associated with a better distribution of 398 fibers in the matrix and thus fewer loads bearing capability. However, this was not 399 the case when hemp core fiber was used. Despite on the lower number of fibers 400 per gram, the use of pine improved the mechanical properties of the final product 


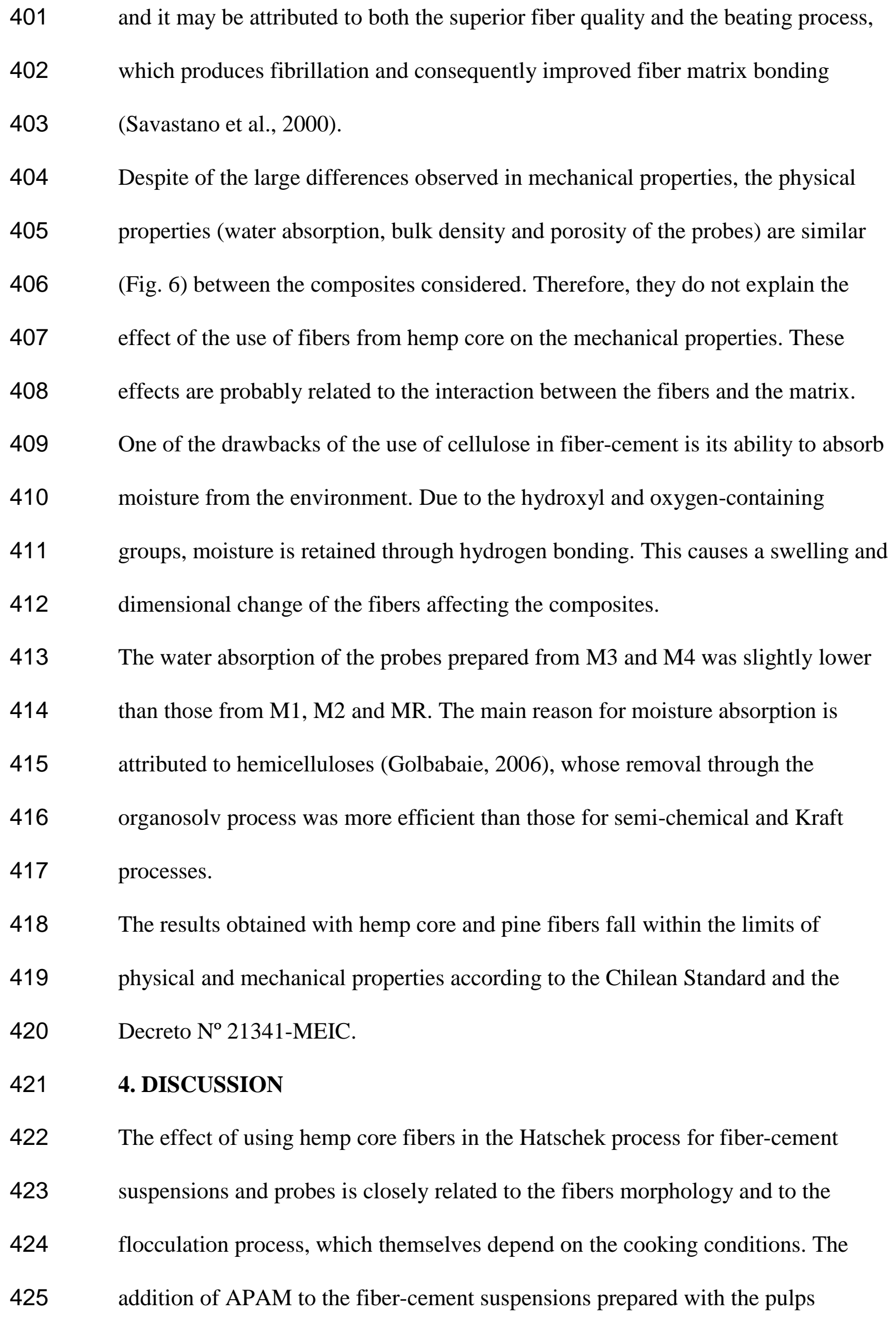


obtained at hard cooking conditions (M1 and M3) induced the formation of small flocs (Fig. 1 and 3), which slowed down the drainage process (Fig. 2) and an enhancement of the compression stage due to the lower strength of the flocs. This increased the retention of solids (Table 5), part of them by means of their interaction with the fiber and the other part through blocking the small voids among flocs. This indicates a better performance in mechanical properties of M1 and M3 fiber-cement probes comparing with the fiber-cement suspensions M2 and M4; however, the drainage is affected.

Albeit a high retention solid was obtained for both M1 and M3, the mechanical properties of the probes obtained from M3 were better than those for M1. This can 436 be explained considering the fibers morphology. Although the main effect on the 437 process is related to the cooking conditions, the pulping process affects the 438 percentage of microfibrills, the length, and the coarseness; therefore, it affects the 439 interaction between fibers and matrix and the dispersion of fibers in the matrix. 440 The increase in the number of microfibrills, and the slight decrease in the length 441 and coarseness increase the surface area, which is available for chemical bonding 442 between the fibers and the matrix. This leads to a more homogeneous surface 443 made of cellulose, which will enhance the adhesion between the fibers and the 444 matrix making this fiber-cement probe be better formed.

445 In addition, there are other mechanisms and phenomena that may explain the 446 higher modulus of rupture of M3 probes induced by the increase in the $447 \quad$ microfibrills:

$448-$ At the level of the microfibrils, the longitudinal tension in the fibers could 449 involve not only tensional stresses, but also torsion effects as well. This 


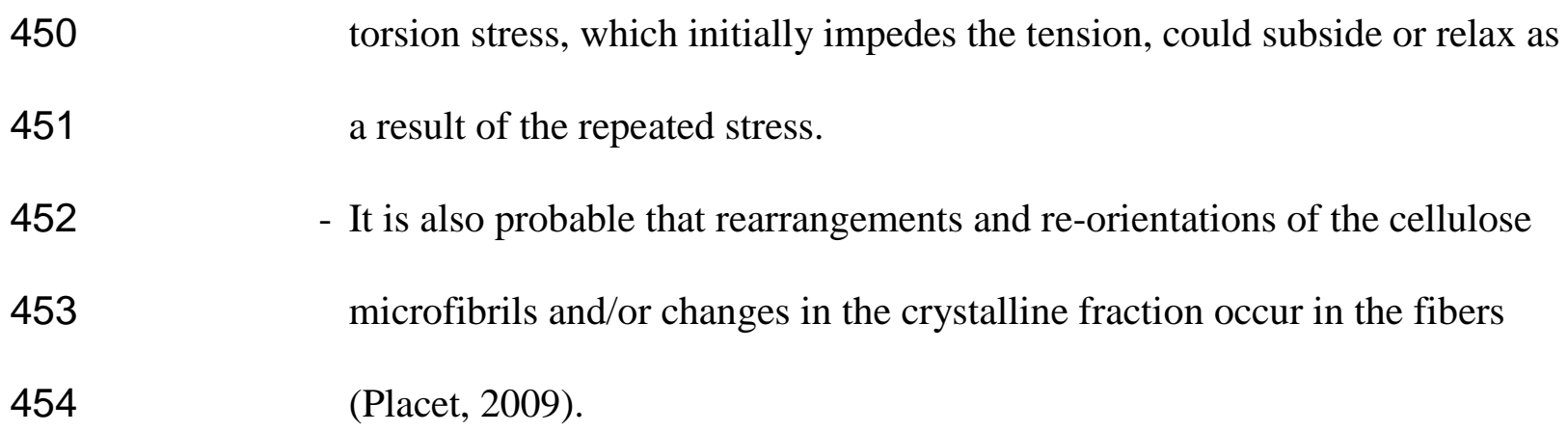

torsion stress, which initially impedes the tension, could subside or relax as a result of the repeated stress.

- It is also probable that rearrangements and re-orientations of the cellulose microfibrils and/or changes in the crystalline fraction occur in the fibers (Placet, 2009).

\section{CONCLUSIONS}

The novelty of this paper lies in the use of agricultural waste materials, particularly, industrial hemp straw (Cannabis Sativa L.), as eco-friendly and renewable source of cellulose fibers in the manufacture of fiber-cement through new environmentally friendly cooking processes.

The cooking process and cooking conditions used to prepare the pulp from the hemp core determined the feasibility of the use of the pulps obtained as source of fibers for fiber-cement manufacture. Cooking the hemp core in ethanolamine at $60 \%$ at $180^{\circ} \mathrm{C}$ during 90 minutes was the optimal pulping process among the options studied for hemp core pulping. These conditions provided the best mechanical properties for hemp core fiber fiber-cement probes. However, a more thorough optimization of the pulping process and pulp conditioning (e.g. refining) based on the effect of fibers on the fiber-cement mechanical properties would be required.

\section{Acknowledgements}

The authors are grateful to the Ministry of Science and Innovation of Spain for the financial support to the Project CTM2007-66793-C03-03 and for funding the scholarship of Rocío Jarabo to accomplish her PhD Thesis. This research is part of a collaborative work between the Universidad Complutense de Madrid and the University of Sao Paulo; the authors would like to acknowledge all assistance 


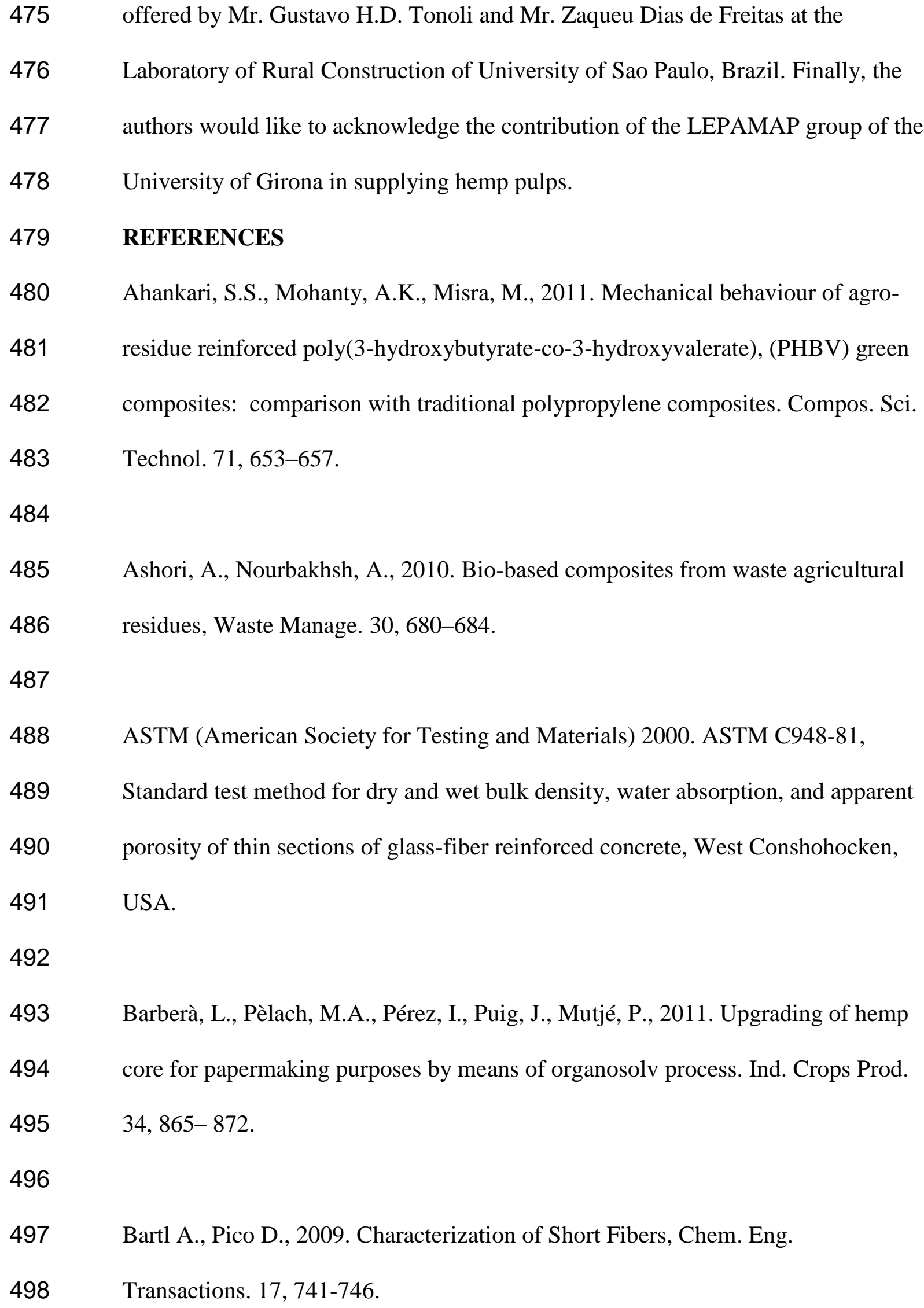


1

2
500 Blanco, A., Fuente, E., Negro, C., Tijero., J, 2002. Flocculation monitoring:

501 focused beam reflectance measurement as a measurement tool. Can. J. Chem. Eng. $502 \quad 80,734-40$

503

504 Carver, G.W., 1941. Auto Body Made of Plastics Resists Denting Under Hard

$505 \quad$ Blows. Popular Mechanics Magazine. 76 (6).

506

507 Cornejo, D.N., Jason, L.H. (Eds), Building Materials: Properties, Performance and

508 Applications, Chapter 9, pp. 299-342.

509

510 Dalmay, P., Smith, A., Chotard, T., Sahay-Turner, P., Gloaguen, V., Krausz, P.,

511 2010. Properties of cellulosic fibre reinforced plaster: influence of hemp or flax

512 fibres on the properties of set gypsum. J. Mater. Sci. 45, 793-803.

513

514 Decreto N² 21341-MEIC, 1992. Láminas planas de fibrocemento.

$515 \quad$ Especificaciones. NCR 193:1992. La Gaceta Nº 127.

516

517 Fuente, E., Jarabo, R., Moral, A., Blanco, A., Izquierdo, L., Negro, C., 2010.

518 Effect of sepiolite on retention and drainage of suspensions of fiber-reinforced

519 cement. Constr. Build. Mater. 24, 2117-2123.

520

521 Golbabaie, M., 2006. Applications of Biocomposites in Building Industry.

522 Department of Plant Agriculture. University of Guelph. 
531

532

533

535

536

537

538

539

540

541

542

543

544 Kerekes, R.J., Schell, C.J., 1992. Characterization of fiber flocculation regimes by

545 a crowding factor. J. Pulp paper Sci. 18(1), 32-38.

Hubbe, M.A., 2007. Flocculation and redispersion of cellulosic fiber suspensions: a review of effects of hydrodynamic shear and polyelectrolytes. BioResour. 2 (2), 296-331.

Jarabo, R., Fuente, E., Moral, A., Blanco, A., Izquierdo, L., Negro, C., 2010.

Effect of sepiolite on the flocculation of suspensions of fibre-reinforced cement.

Cem. Concr. Res. 40, 1524-1530.

Jarabo, R., Monte, M.C., Blanco, A., Negro, C., Tijero, J., 2012. Characterisation of agricultural residues used as a source of fibres for fibre-cement production. Ind. Crops Prod. 36, 14- 21.

Joshi, S.V., Drzal, L.T., Mohanty, A.K., Arora, S., 2004. Are natural fibres composites environmentally superior to glass fibres reinforced composites? Compos. Part A. 35, 371-376.

547 Li, Z., Wang, L., Wang, X., 2004. Compressive and Flexural Properties of Hemp $548 \quad$ Fiber Reinforced Concrete. Fibers Polym. 5 (3), 187-197. 
1

2
549 Li, Z., Wang, X., Wang, L., 2006. Properties of hemp reinforced concrete

$550 \quad$ composites. Compos. Part A. 37, 497-505.

551

552 Moral, A., Monte, M.C., Cabeza, E., Blanco, A., 2010. Morphological

553 characterization of pulps to control paper properties. Cell. Chem. Technol. 44 (10), $554 \quad 473-480$

555

556 Mwaikambo, L.Y., Ansell, M.P., 2003. Hemp fibres reinforced cashew nut shell

557 liquid composites. Compos. Sci. Technol. 63, 1297-1305.

558

559 Mutjé, P., López, A., Vallejos, M.E., López, J.P., Vilaseca, F., 2007. Full

560 exploitation of Cannabis sativa as reinforcement/filler of thermoplastic composite

561 materials. Compos. Part A. 38, 369-377.

562

563 Negro, C., Sánchez, L.M., Fuente, E., Blanco, A., 2005. Effects of flocculants

564 and sizing agents on bending strength of fiber cement composites. Cem. Concr.

$565 \quad$ Res. 35, $2104-2109$.

566

567 Negro, C., Blanco, A., San Pío, I., Tijero, J., 2006. Methodology for flocculant 568 selection in fiber cement manufacture. Cem. Concr. Res. 28, 90-96.

569

570 Negro, C., Blanco, A., San Pío, I., Tijero, J., 2007. In-line flocculation monitoring 571 in a Hatschek machine for fiber-cement manufacture. Compos. Part A - Appl. Sci.

572 Manuf. 38, 26-33. 
574 Norma Chilena, 2006. Fibrocemento - Planchas - Parte 1: Planchas planas -

$575 \quad$ Requisitos. NCh186/1-2003.

576

577 Ouajai, S., Shanks, R. A., 2005. Composition, structure and thermal degradation of 578 hemp cellulose after chemical treatments. Polym. Degrad. Stab. 89, 327-335.

579

580 Pico D., Bartl A., 2011. Image analysis for simultaneous determination of 581 spherical and fibrous particles. Chem. Eng. Transactions. 24, 619-624.

582

583 Placet, V., 2009. Characterization of the thermo-mechanical behaviour of Hemp 584 fibres intended for the manufacturing of high performance composites. Compos. $585 \quad$ Part A. 40, 1111-1118.

586

587 Rabi, J.A., Santos, S.F., Tonoli, G.H.D., Savastano, H.J., 2009. Agricultural 588 wastes as building materials: properties, performance and applications, in:

589

590 Savastano, J.H., Warden, P.G., Coutts, R.S.P., 2000. Brazilian waste Fibres as 591 reinforcement for cement-based composites. Cem. Concr. Compos. 22, 379-384.

592

593 Sedan, D., Pagnoux, C., Smith, A., Chotard, T., 2008. Mechanical properties of 594 hemp fibre reinforced cement: Influence of the fibre/matrix interaction. J. Eur. $595 \quad$ Ceram. Soc. 28, 183-192.

596

597 Swamy, R.N., 1990. Vegetable fibre reinforced cement composites - a false dream 598 or a potential reality? In: Sobral, H.S. (Ed), Proceedings, 2nd International 
599 Symposium on Vegetable Plants and their Fibres as Building Materials. Rilem

$600 \quad$ Proceedings 7. Chapman and Hall, London, 3-8.

601

602 Tonoli G.H.D., Fuente E., Monte C., Savastano Jr. H., Rocco Lahr F.A, Blanco A., 603 2009. Effect of fibre morphology on flocculation of fibre-cement suspensions.

604 Cem. Concr. Res. 39, 1017-1022.

605

606 Tonoli, G.H.D., Santos, S.F., Joaquim, A.P., Savastano, J. H., 2010. Effect of

607 accelerated carbonation on cementitious roofing tiles reinforced with

608 lignocellulosic fibre. Constr. Build. Mat. 24, 193-201.

609

610 Troëdec, M., Peyratout, C.S., Smith, A., Chotard, T., 2009. Influence of various

611 chemical treatments on the interactions between hemp fibres and a lime matrix. J.

612 Europ. Ceramic Soc. 29, 1861-1868.

613

614 Troëdec, M., Rachini, A., Peyratout, C., Rossignol, S., Max, E., Kaftan, O., Fery,

615 A., Smith, A., 2011. Influence of chemical treatments on adhesion properties of

616 hemp fibres. J. Colloid Interface Sci. 356, 303-310.

617

618 Young, R.A., 1997. Utilization of natural fibers: characterization, modification and

619 applications. In: Leao, A.L., Carvalho, F.X., Frollini, E., (Eds), Lignocellulosic-

620 plastics composites. Brasil: USP.

621 


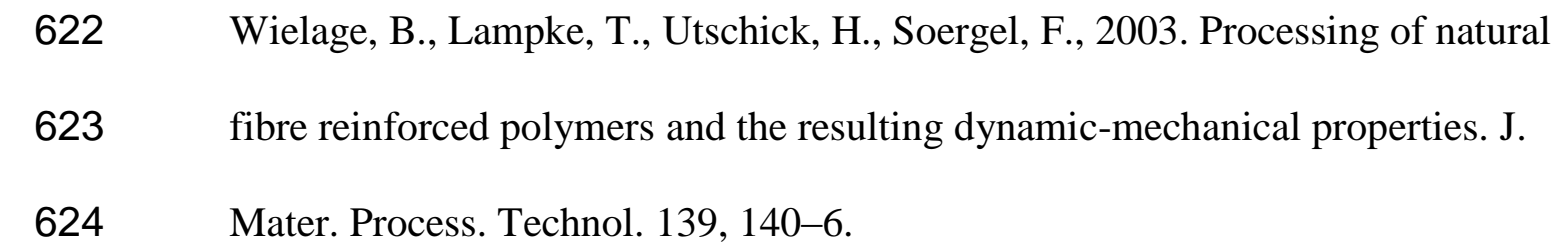


Table 1. Cooking conditions of hemp core using semi-chemical process.

\begin{tabular}{ccccc}
\hline Pulps & $\left.\mathbf{T}^{\circ} \mathbf{C}\right)$ & Time (min.) & NaOH (\%) & Yield (\%) \\
\hline P1 & 180 & 90 & 25 & 49.1 \\
P2 & 140 & 30 & 15 & 68.8 \\
\hline
\end{tabular}


Table 2

Table 2. Cooking conditions of hemp core using organosolv (chemical) process.

\begin{tabular}{ccccc}
\hline Pulps & $\boldsymbol{T}\left({ }^{\boldsymbol{O}} \boldsymbol{C}\right)$ & Time (min.) & Ethanolamine (\%) & Yield (\%) \\
\hline P3 & 180 & 90 & 60 & 28.2 \\
P4 & 155 & 30 & 40 & 53.6 \\
\hline
\end{tabular}


Table 3

Table 3. Composition of the fiber-cement suspensions studied.

\begin{tabular}{lc}
\hline \multicolumn{1}{c}{ Raw materials } & Dry weight (\%) \\
\hline Cellulose & $5 \%$ \\
ASTM II cement & $91 \%$ \\
Microsilica & $4 \%$ \\
\hline
\end{tabular}


Table 4. Morphological characterization of pulps.

\begin{tabular}{lccccc}
\hline PROCESS & \multicolumn{3}{c}{ Semi-chemical } & Organosolv & Kraft \\
\hline PULPS & P1 & P2 & P3 & P4 & PR \\
\hline & FIBERS & & & & \\
\hline Fibers $(\mathbf{1 0} / \mathbf{g})$ & 32.0 & 61.2 & 45.2 & 28.5 & 10.8 \\
Arithm length $(\boldsymbol{\mu m})$ & 356 & 389 & 345 & 352 & 456 \\
Length weighted in length $(\boldsymbol{\mu m})$ & 539 & 574 & 459 & 497 & 1129 \\
Average length weighted in area $\left(\boldsymbol{\mu m}^{\mathbf{2}}\right)$ & 583 & 617 & 472 & 526 & 1344 \\
Average width $(\boldsymbol{\mu m})$ & 19.2 & 29.0 & 24.0 & 27.3 & 25.5 \\
Coarseness $(\mathbf{m g} / \mathbf{m})$ & 0.08 & 0.40 & 0.06 & 0.10 & 0.18 \\
Microfibrills $(\mathbf{\%})$ & 1.38 & 1.66 & 1.68 & 1.48 & 1.62 \\
\hline \multicolumn{7}{l}{ Fines number } & FINES & & & & \\
\hline Fines length $(\boldsymbol{\%})$ & 13149 & 30470 & 8947 & 15474 & 49192 \\
\hline
\end{tabular}


Table 5. Retention and humidity of fiber-cement suspensions.

\begin{tabular}{cccc}
\hline Fiber-cement suspension & Source of fibers & Retention (\%) & Humidity (\%) \\
\hline M1 & P1 & $66.5 \pm 1.87$ & $46.8 \pm 2.05$ \\
M2 & P2 & $29.1 \pm 4.90$ & $63.7 \pm 0.80$ \\
M3 & P3 & $64.7 \pm 1.57$ & $50.5 \pm 0.90$ \\
M4 & P4 & $18.5 \pm 5.70$ & $64.7 \pm 1.33$ \\
MR & Unbleached Kraft pine & $57.3 \pm 2.30$ & $57.9 \pm 1.20$ \\
\hline
\end{tabular}




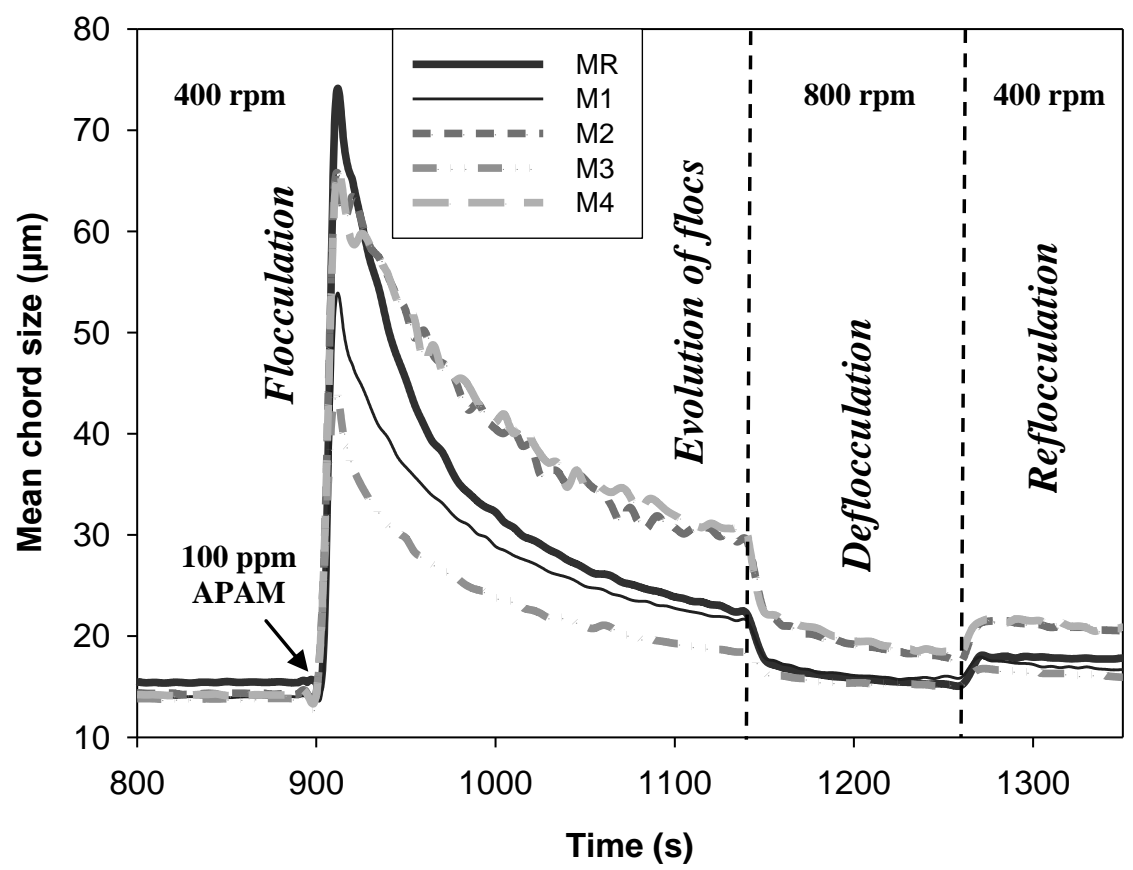

Fig. 1. Evolution of the mean chord size during the flocculation, deflocculation and reflocculation of the fiber-cement suspensions. 
Figure 2

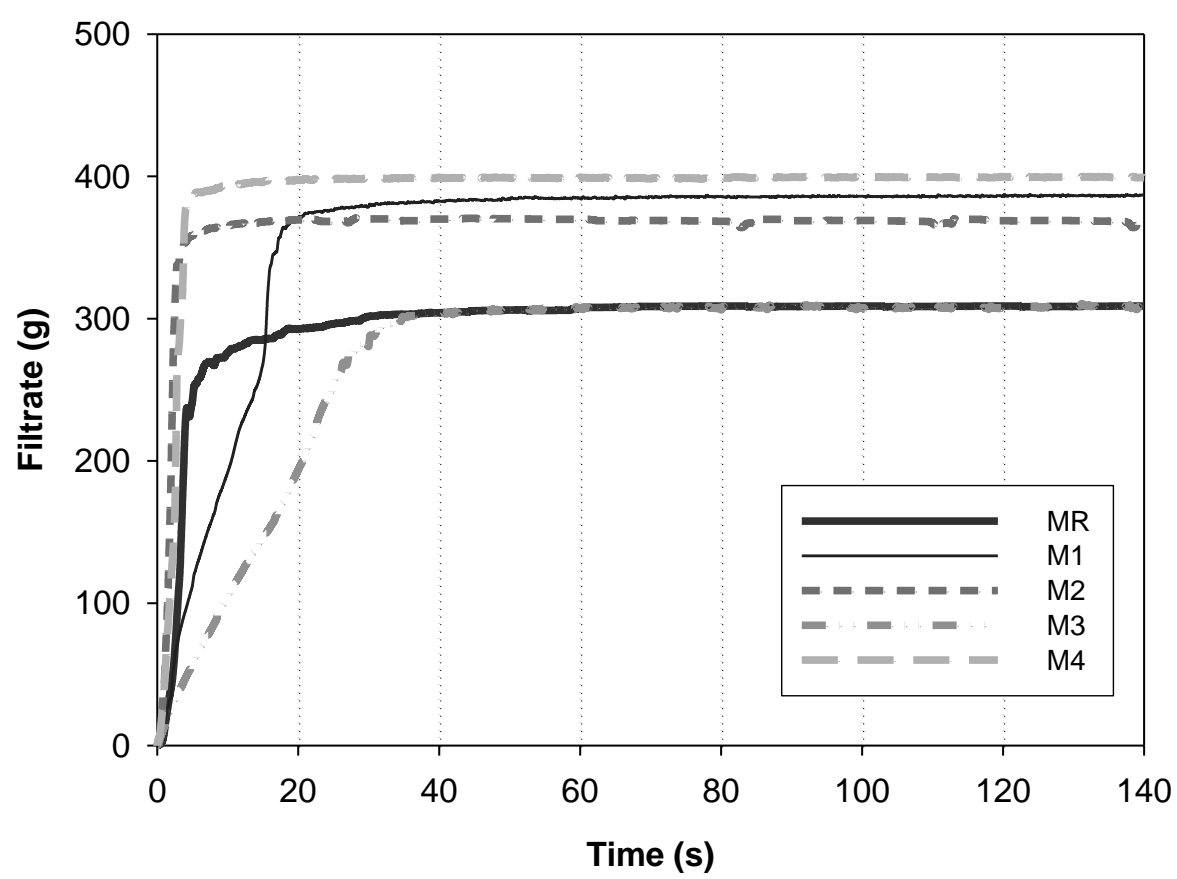

Fig. 2. Drainage curves of the fiber-cement suspensions. 
Figure 3

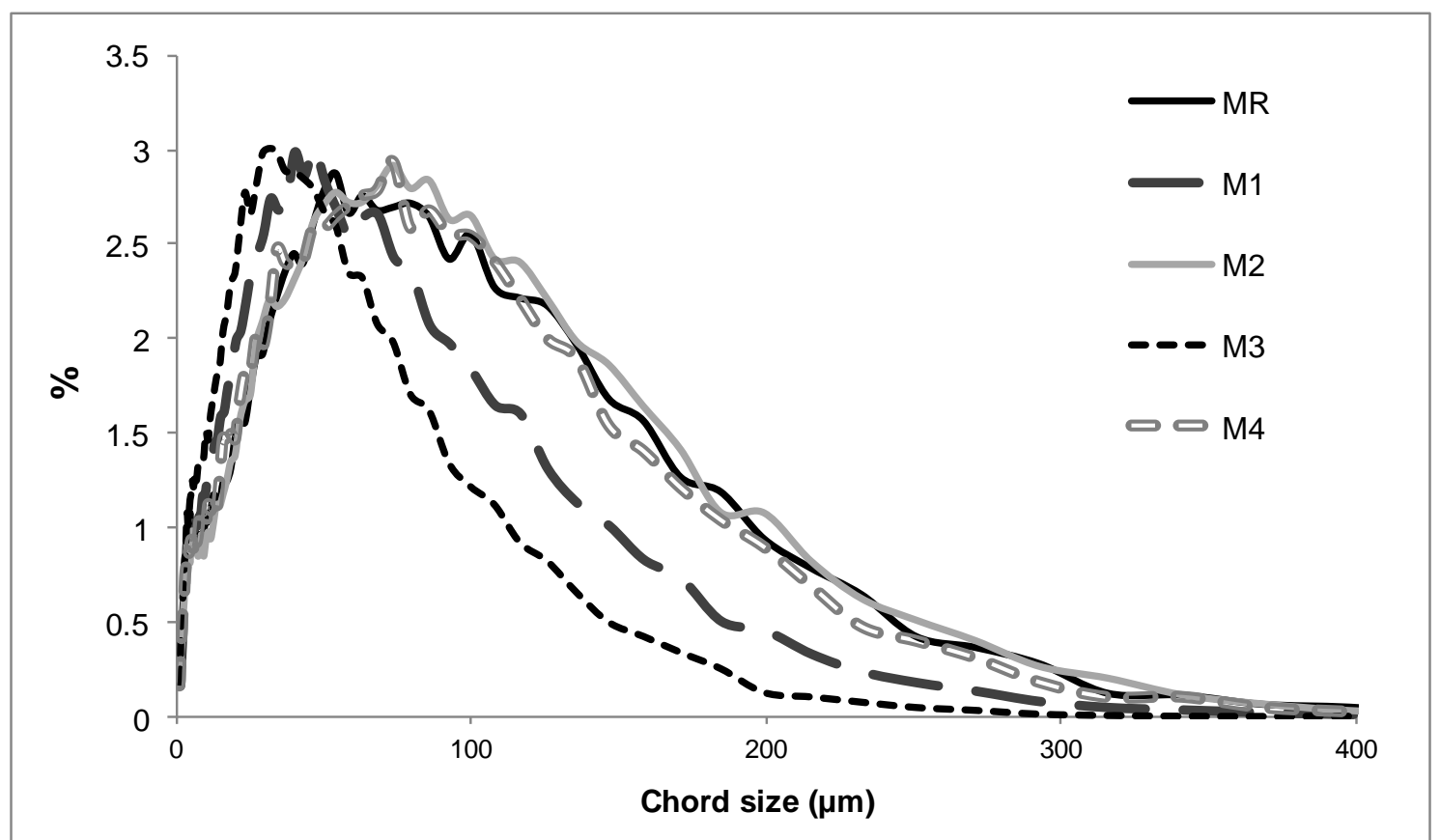

Fig. 3. Chord lengths distribution of the fiber-cement suspensions after the addition of the APAM. 


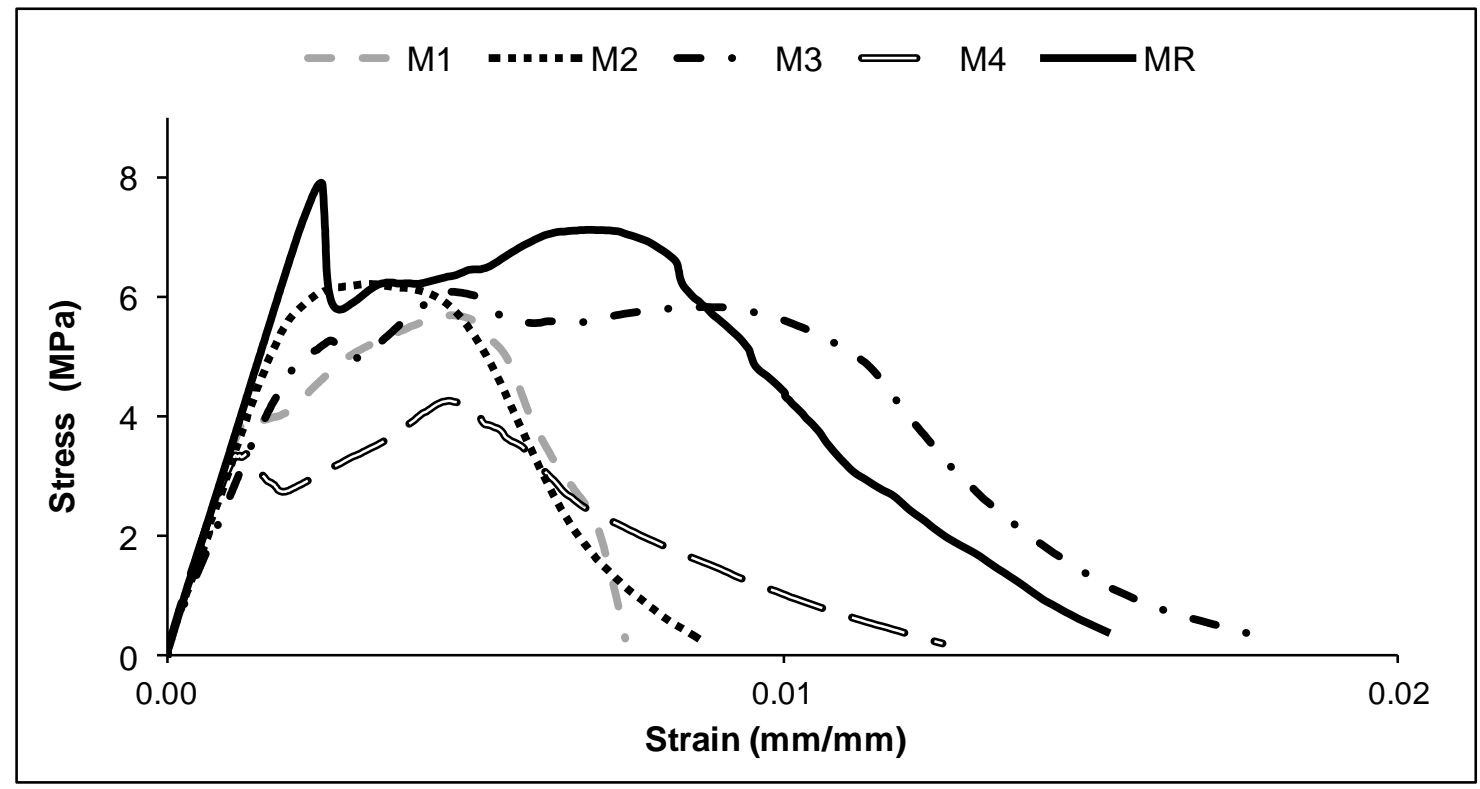

Fig. 4. Stress-Strain curves of the composite reinforced with hemp. 


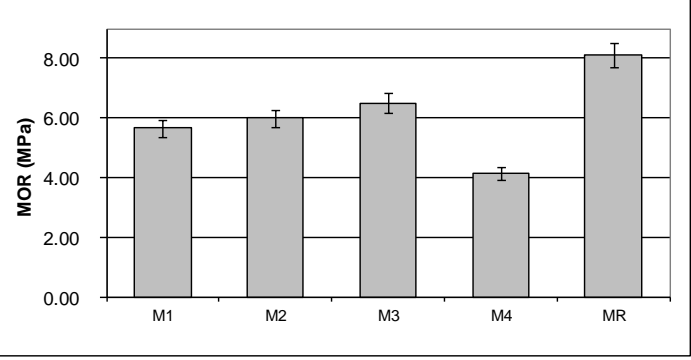

a)

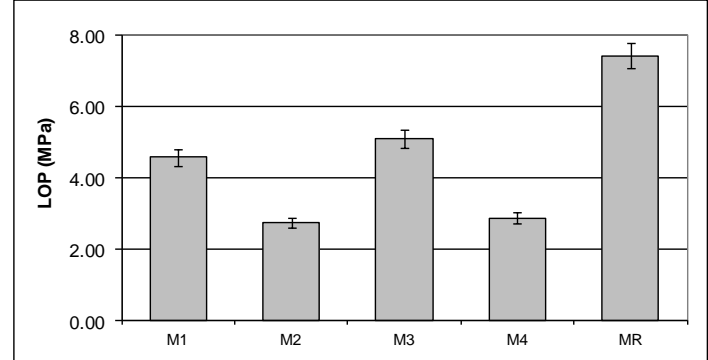

c)

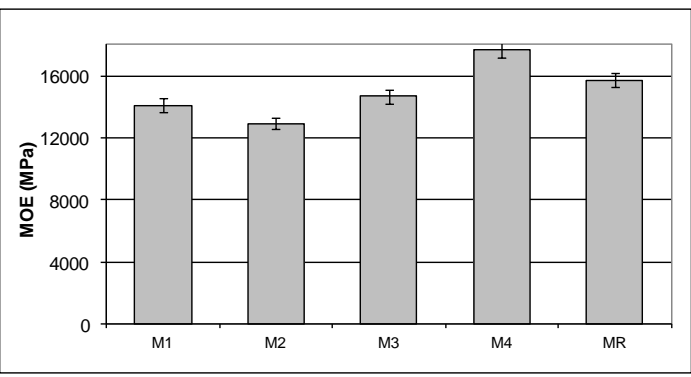

b)

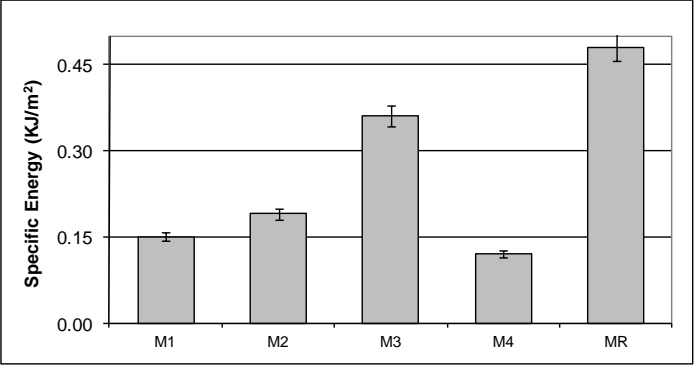

d)

Fig. 5. Effect of the hemp on the mechanical properties: a) modulus of rupture, b) modulus of elasticity, c) limit of proportionality and d) specific energy. 


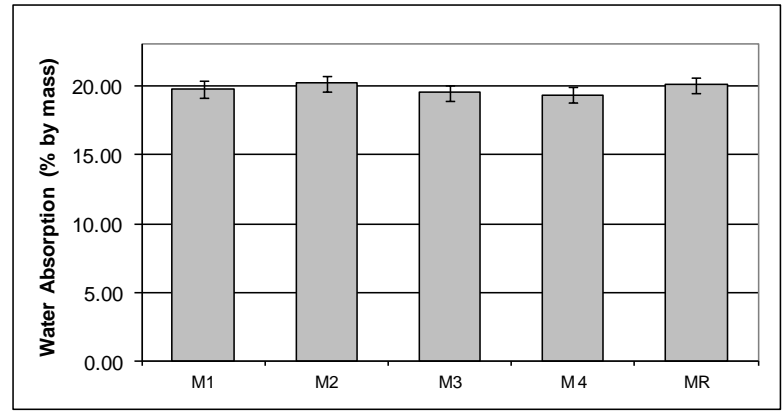

a)

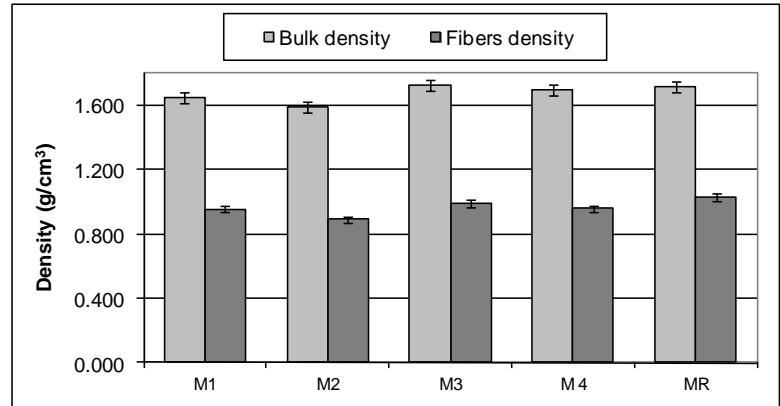

b)

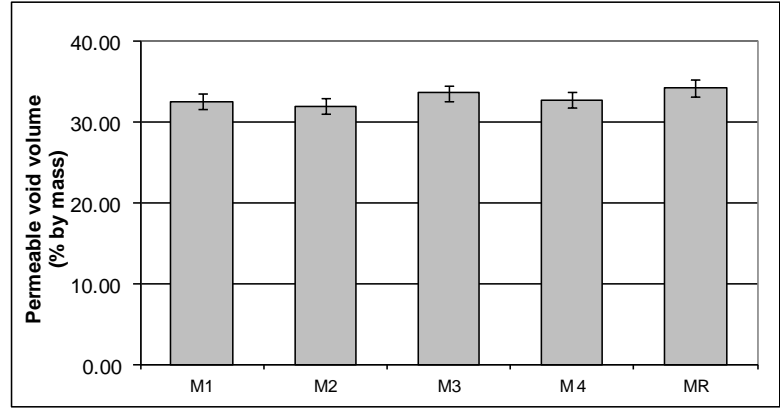

c)

Fig. 6. Effect of the hemp on the physical properties: a) water absorption, b) bulk density and c) permeable void volume. 